http://www.jfas.info

\title{
RECOMMENDED PHYSICAL ACTIVITY AND INTENSITY LEVELS TO REDUCE EXCESS OF BODY FAT AMONGST MALAY FEMALE UNIVERSITY STUDENTS IN MALAYSIA
}

N. Juliana ${ }^{1, *}$, N. I. Akmal ${ }^{1}$, S. M. Johari ${ }^{1}$, S. Azmani ${ }^{1}$, N. A. Umaisara ${ }^{1}$ and N. A. Amin ${ }^{2}$

${ }^{1}$ Faculty of Medicine and Health Sciences, Universiti Sains Islam Malaysia, 55100 Kuala Lumpur, Malaysia

${ }^{2}$ Institute of Medical Science Technology (MESTECH), Universiti Kuala Lumpur, 43000 Kajang, Selangor, Malaysia

Published online: 05 October 2017

\begin{abstract}
This study aims to determine the type of physical activity that best predicts risk of adiposity amongst Malay female university students residing in Klang Valley, Malaysia. A total of 316 female youth aged 18 to 25 years old were recruited for this study. Their physical activities were assessed using Short Questionnaire to Assess Health-Enhancing Physical Activity (SQUASH). Body fat percentage was measured via InBody 270 Body Impedance analyzer machine. Bivariate logistic regression was used to assess the association between physical activities and body fat percentage. Result from this study highlighted that total time per week of commuting $(\mathrm{OR}=2.92,95 \% \mathrm{CI}: 1.18-7.31, \mathrm{p}<0.05)$ and the activity score of leisure time activities $(\mathrm{OR}=2.47,95 \% \mathrm{CI}: 1.37-5.34, \mathrm{p}<0.05)$ are able to predict the risk of adiposity amongst Malay female youth.
\end{abstract}

Keywords: youth; physical activity; adiposity; fat percentage; SQUASH.

Author Correspondence, e-mail: njuliana@usim.edu.my

doi: http://dx.doi.org/10.4314/jfas.v9i4s.53 


\section{INTRODUCTION}

Obesity is one of the alarming health problems in the world. It is estimated that around $13 \%$ of the world's adult population (11\% of men and $15 \%$ of women) were obese in 2014 . Recent report highlights that Malaysia is now the leading nation in South East Asia for obesity [1]. Specifically, in Malaysia, 33.4\% and 17.7\% adults were overweight and obese respectively [2]. Moreover, the prevalence of obesity was significantly higher among females $[20.6 \%$ (95\% CI: 19.5-21.8)] as compared to males [15.0\% (95\% CI: 13.9-16.1] [2].

Despite genetic predisposition, poor physical activity and dietary lifestyles bring more consequences such as early onset of obesity and non-communicable disease. Therefore, one of the best solution to combat obesity is to include daily regular physical activity [3]. Based on Institute of Public Health (2015) male adults were reported to be more active than females [61.7 (95\% CI: 60.3-63.2)]. Hence, this marks the needs for female adults to improve their lifestyle to achieve healthier body mass index (BMI).

$\mathrm{BMI}$ is the most commonly used variable for diagnosing obesity at population level due to its simplicity and association with disease [4]. However, the inconsistency relationship between $\mathrm{BMI}$ and body fat percentage (BF\%) across populations has always been criticized [5-7]. A study in Australia reported that a group of subject with similar BMI range is found to have a significant variation of $\mathrm{BF} \%[8]$.

Theoretically, adiposity has long been suggested to have an inverse relationship with physical activity. The relationship of these two variables is clearly derived from equal balance of energy intake and energy expenditure [9]. Adiposity occurs when the balance disrupted [10]. Therefore, low physical activity may results in adiposity even for those with normal BMI. Thus, this study aims to determine the types of physical activity that best predicts adiposity amongst Malay female university students.

\section{EXPERIMENTAL}

\subsection{Study Design and Subjects}

A total of 316 female youth (Malay) aged 18 to 25 years old were recruited during health screening programme at multiple designated venues in Klang Valley. Subjects were recruited 
through convenient sampling method. Information on the health screening programme were provided through flyers. Data collection was carried out between October 2016 to January 2017. Ethical approval was obtained from institutional ethical board (USIM/REC/0416-3) and informed consent were obtained from all participants' prior data collection. Inclusion criteria are female aged 18-25 years old based on United Nation classification for youth [24]. The exclusion criteria includes pregnant youth, lactating, mental health disorder, non-communicable disease, cancers, eating disorders and any injuries or disabilities that effect their body movement to perform physical activity. Standardized pre-tested questionnaire was used by trained interviewers to obtain demographic data. Physical activity (SQUASH) is used to assess subjects' physical activity.

\subsection{Identification of Anthropometric Measurement}

Anthropometric measurements taken include height measurement using BSM 170 stadiometer (Inbody Co. Ltd, Korea). Body composition that were measured using InBody 270 Body Impedance analyzer machine (Inbody Co. Ltd, Korea). Those instruments were calibrated every measurement sessions. Body fat percentage for female youth is classified using based on [25]. Ranges are $21-32 \%$ for healthy, $33-39 \%$ for overfat and $>39 \%$ for obese.

\subsection{Identification of Physical Activity}

Subjects' physical activity was measured using Short Questionnaire to Assess Health-Enhancement Activities (SQUASH) [26]. Four domains of activities are included in SQUASH such as commuting (walking or cycling), physical activity at work or at school, household activities and leisure time activities (sports, walking, gardening). Subjects were interviewed for the number of days a week they engaged in the activities and also the average time they spent each session on each activites (hours and minutes). Hence, the intensity score is calculated based on classification of the MET levels (low, moderate, high). Results from the SQUASH is presented in total times per week and activity score [26].

\subsection{Statistical Analysis}

All analyses were performed using Statistical Analysis for Social Sciences (SPSS) software version 23.0 and Medcalc software. Descriptive analysis was carried out on demography, anthropometry and physical activity. Mann Whitney test was used to compare means of 
related factors to adiposity. ROC analysis test was performed to identify the cut-off point for level of physical activity of each domains. Bivariate logistic regression analysis was employed to determine the relative predictors of adiposity at $p<0.05$.

\section{RESULTS AND DISCUSSION}

A total of 316 Malay female participants aged 18 to 22 years old were involved in this study. Mean for BMI and fat percentage are $22.6 \mathrm{~kg} / \mathrm{m}^{2}$ and $35.1 \%$ respectively. The prevalence of overweight and obesity in this study $17.1 \%$ and $8.5 \%$. Based on fat percentage cut-off value of $\geq 32 \%, 113(35.8 \%)$ subjects are identified as having high adiposity. As reported in Table 1, subjects with normal BMI has significantly lower fat percentage (med: 28.1 $\pm 4.6, \mathrm{p}<0.05$ ) than those who are overweight and obese (med: $38.3 \pm 8.8, \mathrm{p}<0.001$ ). Level of physical activity (minutes/week) for all domains are found to be significantly higher $(\mathrm{p}<0.001)$ in subjects with normal adiposity level. Parallel to that, the activity score for participants with normal adiposity level is also significantly higher $(p<0.001)$ than in subjects with high adiposity.

Table 1. Median difference of body composition and physical activities between normal group and group with high adiposity. Result is presented as median (interquartile range)

\begin{tabular}{cccc}
\hline Items & $\begin{array}{c}\text { Normal } \\
(\mathbf{n}=\mathbf{1 1 3})\end{array}$ & $\begin{array}{c}\text { Adiposity } \geq \mathbf{3 2 \%} \\
(\mathbf{n}=\mathbf{2 0 3})\end{array}$ & $\mathbf{p}^{\text {a Value }}$ \\
& Body composition & \\
BMI $\left(\mathrm{kg} / \mathrm{m}^{2}\right)$ & $28.1(4.6)$ & $21.2(4.4)$ & $0.008^{*}$ \\
Fat percentage (\%) & $22.5(6.7)$ & $38.3(8.8)$ & $<0.001^{*}$ \\
Physical activities (minutes/week) & \\
Commuting & $100(25)$ & $70(50)$ & $<0.001^{*}$ \\
Leisure time activities & $180(265)$ & $30(120)$ & $<0.001^{*}$ \\
Household activities & $225(353)$ & $150(230)$ & $<0.001^{*}$ \\
Activities at work/school & $600(1438)$ & $225(450)$ & $0.002^{*}$ \\
Total item & $1519(2090)$ & $578(890)$ & $<0.001^{*}$
\end{tabular}

Physical activities (activity score) 


\begin{tabular}{cccc}
\hline Commuting & $200(50)$ & $140(100)$ & $<0.001^{*}$ \\
Leisure time activities & $320(695)$ & $60(330)$ & $<0.001^{*}$ \\
Household activities & $570(850)$ & $420(570)$ & $<0.001^{*}$ \\
Activities at work/school & $1200(2850)$ & $450(700)$ & $<0.001^{*}$ \\
Total item & $3290(4458)$ & $1220(1870)$ & $<0.001^{*}$ \\
\hline
\end{tabular}

${ }^{a}$ Mann-whitney test; * significant mean difference at level $\mathrm{p}<0.05$

$\mathrm{BMI}=$ Body mass index

Receiver Operating Characteristics (ROC) analysis was used to establish the cut-off points for all physical activity domains. Data were examined for all domains. The best cut-off points from each domains were chosen based on the optimal levels of sensitivity and specificity (Table 2). All of these cut-off points obtained were then used to investigate the predictors of various independent variables and the incidence of higher adiposity (i.e. fat percentage $\geq$ $32 \%$ ). However, for leisure time activity, the cut-off points of 150 minutes/week (WHO recommendation) was used.

Table 2. Cut-off points for physical activity domains based on Receiver Operating Characteristics (ROC) value

\begin{tabular}{cccc}
\hline Items & ROC Value & Specificity & Sensitivity \\
\hline \multicolumn{2}{c}{ Physical activities (minutes/week) } & \\
Commuting & 90 & 67.8 & 74.6 \\
Household activities & 135 & 49.0 & 73.7 \\
Activities at work/school & 1020 & 85.6 & 43.9 \\
Total item & 1145 & 74.3 & 55.3 \\
Physical activities (activity score) & \\
Commuting & 180 & 67.3 & 73.7 \\
Household activities & 780 & 80.2 & 40.4 \\
Activities at work/school & 1920 & 86.1 & 45.6 \\
Leisure time activities & 120 & 64.4 & 68.4 \\
Total item & 2600 & 75.2 & 57.0 \\
\hline
\end{tabular}

As shown in Table 3, results from binary logistic regression reveals that total time for 
commuting $(\mathrm{OR}=2.92,95 \% \mathrm{CI}: 1.18-7.31, \mathrm{p}<0.05)$ and leisure time score $(\mathrm{OR}=2.47,95 \%$ CI: $1.37-5.34, p<0.05)$ are found to have positive effects towards reducing adiposity.

Table 3. Binary logistic regression of physical activity domains

\begin{tabular}{|c|c|c|c|}
\hline Items & Crude OR & $95 \%$ CI & p Value \\
\hline \multicolumn{4}{|c|}{ Physical activities (minutes/week) } \\
\hline Commuting & 2.92 & $1.18-7.31$ & $0.02 *$ \\
\hline \multicolumn{4}{|l|}{$90<$} \\
\hline \multicolumn{4}{|l|}{$90 \geq$} \\
\hline Leisure Time activities & 0.94 & $0.49-1.92$ & 0.94 \\
\hline \multicolumn{4}{|l|}{$150 \geq$} \\
\hline \multicolumn{4}{|l|}{$150<$} \\
\hline Household activities & 1.60 & $0.85-0.63$ & 0.15 \\
\hline \multicolumn{4}{|l|}{$135 \geq$} \\
\hline \multicolumn{4}{|l|}{$135<$} \\
\hline Activities at work/school & 1.48 & $0.31-5.99$ & 0.25 \\
\hline \multicolumn{4}{|l|}{$1020 \geq$} \\
\hline \multicolumn{4}{|l|}{$1020<$} \\
\hline Total item & 0.45 & $0.12-1.72$ & 0.68 \\
\hline \multicolumn{4}{|l|}{$1145 \geq$} \\
\hline \multicolumn{4}{|l|}{$1145<$} \\
\hline \multicolumn{4}{|c|}{ Physical activities (activity score) } \\
\hline Commuting & 1.65 & $0.67-4.05$ & 0.27 \\
\hline \multicolumn{4}{|l|}{$180<$} \\
\hline \multicolumn{4}{|l|}{$180 \geq$} \\
\hline Leisure time activities & 2.70 & $1.37-5.34$ & $0.004 *$ \\
\hline \multicolumn{4}{|l|}{$120 \geq$} \\
\hline \multicolumn{4}{|l|}{$120<$} \\
\hline Household activities & 1.89 & $0.94-3.83$ & 0.76 \\
\hline $780 \geq$ & & & \\
\hline
\end{tabular}




\begin{tabular}{|c|c|c|c|}
\hline \multicolumn{4}{|l|}{$780<$} \\
\hline Activities at work/school & 1.99 & $0.44-8.98$ & 0.37 \\
\hline \multicolumn{4}{|l|}{$1920 \geq$} \\
\hline \multicolumn{4}{|l|}{$1920<$} \\
\hline Total item & 1.38 & $0.36-5.28$ & 0.64 \\
\hline \multicolumn{4}{|l|}{$2600 \geq$} \\
\hline $2600<$ & & & \\
\hline
\end{tabular}

*significant at $\mathrm{p}<0.05$ level

$\mathrm{OR}=$ odds ratio

$\mathrm{CI}=$ confidence interval

In this study, the mean BMI of $21.95 \mathrm{~kg} / \mathrm{m}^{2}$ and $16.98 \%$ are found to be higher than the previous study done among female students in East Malaysia. [11]. The prevalence of high adiposity in our study (35.8\%) is also higher than a recent study in Taiwan (2016) among young female adults which is reported at $27.3 \%$ [12]. This indicates that about one third of this population which are all young adults are at high risk for non-communicable and cancer diseases [13-14].

Many studies have shown that BMI is a reasonable index of adiposity [15-16] given that body weight and height are simple, inexpensive, safe and practical measurements to acquire, particularly for groups with limited access to health care. However, in our findings BMI did not reflect adiposity in which participants with normal BMI were found to have higher adiposity. According to previous studies, BMI gives limited information about body composition because it does not discriminate between fat and lean mass [17-18]. Thus, the determination of body fat percentage is crucial for early screening of overweight and obesity among young adults.

This present study revealed that female university students with normal fat percentage are physically active. In agreement to that, in [19] also reported that most youth spent most of their time being active during leisure time or when at school and/or work. Specifically, the "leisure time activity" domain is found to be higher (180 MET/minute) than the recommended physical activity level of $150 \mathrm{MET} /$ minutes by WHO. Being university students the likelihood 
of leisure time physical activity is positively associated with the strength of beliefs in the health benefits [20].

This study clearly indicate that physical activity is part of important predictors for adiposity level among female university students. Ideally, positive changes in lifestyle must include the component of physical activity. Hence, the lifestyle changes will persist to adult years and further create a healthy future generation [21]. Recent study in the Northeast also reported that despite multiple awareness programmes highlight the benefits of exercise, only $35 \%$ of university students had a regular schedule of physical activity. Furthermore, there better adherence to exercise by males (40\%) than females (32\%) students [22]. Another study showed that most students had light physical activity levels, particularly women [23]. Light physical activity such as walking may not provide desirable protection against disease as metabolism of fat also depends on the intensity of activity. Based on the young adult population in this study, total time of physical activity alone is found not to be a strong predictor for adiposity. However, the integration of total time and the intensity of physical activity exert significant effect on the adiposity level. Besides that, the cut-off point for total time in commuting of $90 \mathrm{~min} /$ week should also be included as part of the recommendation to reduce adiposity.

\section{CONCLUSION}

Body fat percentage provides better understanding than BMI on the relationship between body composition and individual physical activity. Female university students that are generally young adults reflect their inactivity with higher body fat percentage rather than BMI. Multiple domains of physical activity showed significant difference between different adiposity statuses of the selected population. Two strong predictors of excess body fat identified are the total time taken for commuting and the activity score of leisure time activity. Thus, combination of this two predictors will provide promising result in lowering adiposity.

\section{ACKNOWLEDGEMENTS}

This project was partly funded by USIM/FRGS/FPSK/32/51415 research grant, awarded to 
Islamic Science University of Malaysia (USIM) by Ministry of Higher Education. The authors also acknowledge the invaluable assistance of co-researchers. Many thanks are extended to the participants, fieldworkers and others involved in the data collection.

\section{REFERENCES}

[1] Ng M, Fleming T, Robinson M, Thomson B, Graetz N. Global, regional and national prevalence of overweight and obesity in children and adults 1980-2013: A systematic analysis. Lancet, 2014, 384(9945):766-781

[2] Institute for Public Health. National health and morbidity survey 2015. Putrajaya: Ministry of Health, 2015

[3] Hills A P, Byrne N M, Lindstrom R, Hill J O. 'Small changes' to diet and physical activity behaviors for weight management. Obesity Facts, 2013, 6(3):228-238

[4] World Health Organization (WHO). Obesity: Preventing and managing the global epidemic. Geneva: WHO, 2000

[5] Deurenberg-Yap M, Schmidt G, van Staveren W A, Deurenberg P. The paradox of low body mass index and high body fat percentage among Chinese, Malays and Indians in Singapore. International Journal of Obesity, 2000, 24(8):1011-1017

[6] Rush E C, Goedecke J H, Jennings C, Micklesfield L, Dugas L, Lambert E V, Plank L D. BMI, fat and muscle differences in urban women of five ethnicities from two countries. International Journal of Obesity, 2007, 31(8):1232-1239

[7] Fernández J R, Heo M, Heymsfield S B, Pierson R N, Pi-Sunyer F X, Wang Z M, Wang J, Hayes M, Allison D B, Gallagher D. Is percentage body fat differentially related to body mass index in Hispanic Americans, African Americans, and European Americans? American Journal of Clinical Nutrition, 2003, 77(1):71-75

[8] Piers L S, Rowley K G, Soares M J, O'Dea K. Relation of adiposity and body fat distribution to body mass index in Australians of Aboriginal and European ancestry. European Journal of Clinical Nutrition, 2003, 57(8):956-963

[9] Tiruneh G. The relation between physical activity and body mass index: Issues in model specification. International Journal on Disability and Human Development, 2009, 
$8(3): 267-276$

[10] Esparza J, Fox C, Harper I T, Bennett P H, Schulz L O, Valencia M E, Ravussin E. Daily energy expenditure in Mexican and USA Pima Indians: Low physical activity as a possible cause of obesity. International Journal of Obesity, 2000, 24(1):55-59

[11] Zin T, Yusuff A S, Myint T, Naing D K, Htay K, Wynn A A. Body fat percentage, BMI and skinfold thickness among medical students in Sabah, Malaysia. South East Asia Journal of Public Health, 2015, 4(1):35-40

[12] Hung S P, Chen C Y, Guo F R, Chang C I, Jan C F. Combine body mass index and body fat percentage measures to improve the accuracy of obesity screening in young adults. Obesity Research and Clinical Practice, 2017, 11(1):11-18

[13] Juliana N, Shahar S, Sahar M A, Ghazali A R, Manaf Z A, Noah R M. 'Her shape'intervention programme for obese women with high breast adiposity. Asia Pacific Journal of Clinical Nutrition, 2017, 26(2):278-286

[14] Temple V A, Walkley J W, Greenway K. Body mass index as an indicator of adiposity among adults with intellectual disability. Journal of Intellectual and Developmental Disability, 2010, 35(2):116-120

[15] Bedogni G, Pietrobelli A, Heymsfield S B, Borghi A, Manzieri A M, Morini P, Battistini N, Salvioli G. Is body mass index a measure of adiposity in elderly women? Obesity, 2001, $9(1): 17-20$

[16] Shah N R, Braverman E R. Measuring adiposity in patients: The utility of body mass index (BMI), percent body fat, and leptin. Plos One, 2012, 7(4):1-8

[17] Flegal K M, Shepherd J A, Looker A C, Graubard B I, Borrud L G, Ogden C L, Harris T

B, Everhart J E, Schenker N. Comparisons of percentage body fat, body mass index, waist circumference, and waist-stature ratio in adults. American Journal of Clinical Nutrition, 2009, 89(2):500-508

[18] Romero-Corral A, Somers V K, Sierra-Johnson J, Thomas R J, Bailey K R, Collazo-Clavell M L, Allison T G, Korinek J, Batsis J A, Lopez-Jimenez F. Accuracy of body mass index to diagnose obesity in the US adult population. International Journal of Obesity, 2008, 32(6):959-966 
[19] Campbell N, Gaston A, Gray C, Rush E, Maddison R, Prapavessis H. The Short QUestionnaire to ASsess Health-enhancing (SQUASH) physical activity in adolescents: A validation using doubly labeled water. Journal of Physical Activity and Health, 2016, 13(2):154-158

[20] Haase A, Steptoe A, Sallis J F, Wardle J. Leisure-time physical activity in university students from 23 countries: Associations with health beliefs, risk awareness, and national economic development. Preventive Medicine, 2004, 39(1):182-190

[21] Fabián C, Pagán I, Ríos J L, Betancourt J, Cruz S Y, González A M, Palacios C, González M J, Rivera-Soto $\mathrm{W}$ T. Dietary patterns and their association with sociodemographic characteristics and perceived academic stress of college students in Puerto Rico. Puerto Rico Health Sciences Journal, 2013, 32(1):36-43

[22] Pinto B M, Cherico N P, Szymanski L, Marcus B H. Longitudinal changes in college students' exercise participation. Journal of American College Health, 1998, 47(1):23-27

[23] Abdel-Megeid F Y, Abdelkarem H M, El-Fetouh A M. Unhealthy nutritional habits in university students are a risk factor for cardiovascular diseases. Saudi Medical Journal, 2011, 32(6):621-627

[24] Petry N M. A Comparison of young, middle-aged, and older adult treatment-seeking pathological gamblers. Gerontologist, 2002, 42(1):92-99

[12] Gallagher D, Heymsfield S B, Heo M, Jebb S A, Murgatroyd P R, Sakamoto Y. Healthy percentage body fat ranges: An approach for developing guidelines based on body mass index. American Journal of Clinical Nutrition, 2000, 72(3):694-701

[26] Wendel-Vos G C W, Schuit A J, Saris W H M, Kromhout D. Reproducibility and relative validity of the short questionnaire to assess health-enhancing physical activity. Journal of Clinical Epidemiology, 2003, 56(12):1163-1169.

\section{How to cite this article:}

Juliana N, Akmal NI, Johari SM, Azmani S, Umaisara NA, Amin NA. Recommended Physical Activity and Intensity Levels to Reduce Excess of Body Fat Amongst Malay Female University Students in Malaysia. J. Fundam. Appl. Sci., 2017, 9(4S), 111-121. 